\title{
Local production of CCL3, CCL11, and IFN- $\gamma$ correlates with disease severity in murine parainfluenza virus infection
}

\author{
Manika Suryadevara ${ }^{1 *}$, Cynthia A Bonville ${ }^{1}$, Helene F Rosenberg ${ }^{2}$ and Joseph B Domachowske ${ }^{1}$
}

\begin{abstract}
Background: Using a murine model of parainfluenza virus infection (mPIV1 or Sendai virus; SeV), we compared the inflammatory responses to lethal and sub-lethal infections in inbred DBA/2 mice.

Methods: Mice were intranasally inoculated with either $1.6 \times 10^{3}$ or $1.6 \times 10^{5}$ infectious units (IU) of SeV or diluent control. Clinical data including daily weights, oxygen saturation, and lung function via whole body plethysmography were collected on days 0, 3-7, and 9-14. Clarified whole lung homogenates were evaluated for inflammatory markers by enzyme-linked immunoassay (ELISA). Data were analyzed using ANOVA or Student t-tests, as appropriate.

Results: Mice inoculated with $1.6 \times 10^{5} \mathrm{IU}$ of SeV developed a lethal infection with $100 \%$ mortality by day 7 , while mice inoculated with $1.6 \times 10^{3} \mathrm{IU}$ developed a clinically significant infection, with universal weight loss but only $32 \%$ mortality. Interestingly, peak virus recovery from the lungs of mice inoculated with $1.6 \times 10^{5} \mathrm{IU}$ of SeV did not differ substantially from that detected in mice that received the 100-fold lower inoculum. In contrast, concentrations of CCL5 (RANTES), CCL11 (eotaxin), interferon- $\gamma$, CXCL10 (IP-10), and CCL3 (MIP-1a) were significantly higher in lung tissue homogenates from mice inoculated with $1.6 \times 10^{5} \mathrm{IU}(\mathrm{p}<0.05)$. In the lethal infection, levels of CCL11, interferon- $\gamma$ and CCL3 all correlated strongly with disease severity.

Conclusion: We observed that severity of SeV-infection in DBA/2 mice was not associated with virus recovery but rather with the levels of proinflammatory cytokines, specifically CCL11, interferon- $\gamma$ and CCL3, detected in lung tissue in response to SeV infection.
\end{abstract}

Keywords: Sendai virus, Parainfluenza virus, CCL3, MIP-1a, CCL11, Eotaxin, Interferon- $\gamma$

\section{Background}

Human parainfluenza viruses (hPIV), of the Paramyxovirus family, cause a spectrum of illness from mild upper respiratory infection and otitis media to severe laryngotracheobronchitis and bronchiolitis [1-4]. HPIV can be detected in up to $30 \%$ of children hospitalized for acute respiratory tract infection, second in etiology of infection only to respiratory syncytial virus (RSV) [1-4]. Pathogenesis of hPIV is believed to include both direct virus cytotoxicity and subsequent host immune response; treatment

\footnotetext{
* Correspondence: suryadem@upstate.edu

'Department of Pediatrics, SUNY Upstate Medical University, 750 East Adams Street, Syracuse, NY 13210, USA

Full list of author information is available at the end of the article
}

with glucocorticoids provides clinical benefit in some circumstances [5-7].

Airway epithelium infected with hPIV produces a variety of cytokines and chemokines that act as immune mediators in response to infection [8]. We have previously reported increased concentrations of interleukin-6 (IL-6), CCL5 (regulated and normal T cell expressed and secreted (RANTES)), CXCL8 (interleukin-8), CXCL9 (monokine induced by gamma-interferon (MIG)), and CCL3 (macrophage inflammatory protein-1 $\alpha(\mathrm{MIP}-1 \alpha))$ from the nasal wash specimens of children infected with hPIV when compared to uninfected controls [9]. These cytokines contribute to the recruitment of inflammatory cells to the infected epithelium and, in the case of CXCL8, is associated with illness severity [9].

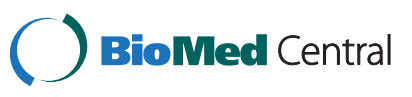


Sendai virus $(\mathrm{SeV})$, murine PIV, induces acute bronchiolitis and interstitial pneumonia in rodents, and has been used to model severe human hPIV infection [10-12]. Differences in susceptibility to $\mathrm{SeV}$ infection among mouse strains exist, with C57BL/6 mice being more resistant and DBA/2 mice being more susceptible to infection $[11,13,14]$. SeV is known to be a strong inducer of various cytokines/chemokines, including interferon- $\Upsilon$, IL-2, TNF- $\alpha$, IL-6, and IL-10 [12]. Simon and colleagues showed that $\mathrm{SeV}$ infection in the susceptible DBA/2 mice resulted in a vigorous inflammatory response, specifically with increased production of IL$1 \beta$, IL-2, IL- 6 , interferon- $\gamma$, and TNF- $\alpha$, with subsequent mortality from severe lung injury. Similarly, in comparison to the resistant $\mathrm{C} 57 \mathrm{BL} / 6$ mice, up-regulation of CCL3 and CCL11 was seen in the SeV-infected DBA/2 mice [11].

Understanding host inflammatory responses that contribute to illness severity offers the potential to identify future therapeutic targets. Toward this end, we compared the inflammatory responses to both sub-lethal and lethal $\mathrm{SeV}$ infection in mice.

\section{Results}

Clinical parameters of SeV-infected mice

Mice inoculated with $1.6 \times 10^{3} \mathrm{IU}$ of $\mathrm{SeV}$ developed a clinically significant infection with $32 \%$ mortality in the 14-day period (Figure 1A, p < 0.05). When compared to control mice, the infected mice showed changes in weight $(\mathrm{p}<0.05)$, oxygen saturations $(\mathrm{p}<0.05)$, and Penh values $(\mathrm{p}<0.05)$. Clinical symptoms in the infected mice peaked between days 6 and 10, with nadir mean weight change from baseline of $-12 \%$, nadir mean oxygen saturation of $81 \%$, and peak Penh values at 4 -fold over baseline. Following these points, clinical parameters were noted to improve, although symptoms did not resolve completely; by day 14, mean oxygen saturations of infected mice remained statistically lower than those of control mice, and mean Penh values in infected mice remained at 1.5-fold over baseline (Figure 1).

Mice inoculated with $1.6 \times 10^{5} \mathrm{IU}$ of $\mathrm{SeV}$ developed a lethal infection, with $100 \%$ mortality by day 7 . These mice sustained significantly more weight loss than mice inoculated with $1.6 \times 10^{3} \mathrm{IU}$ of $\mathrm{SeV}$, with a nadir mean weight change from baseline of $-28 \%(\mathrm{p}<0.05)$. Similarly, by day
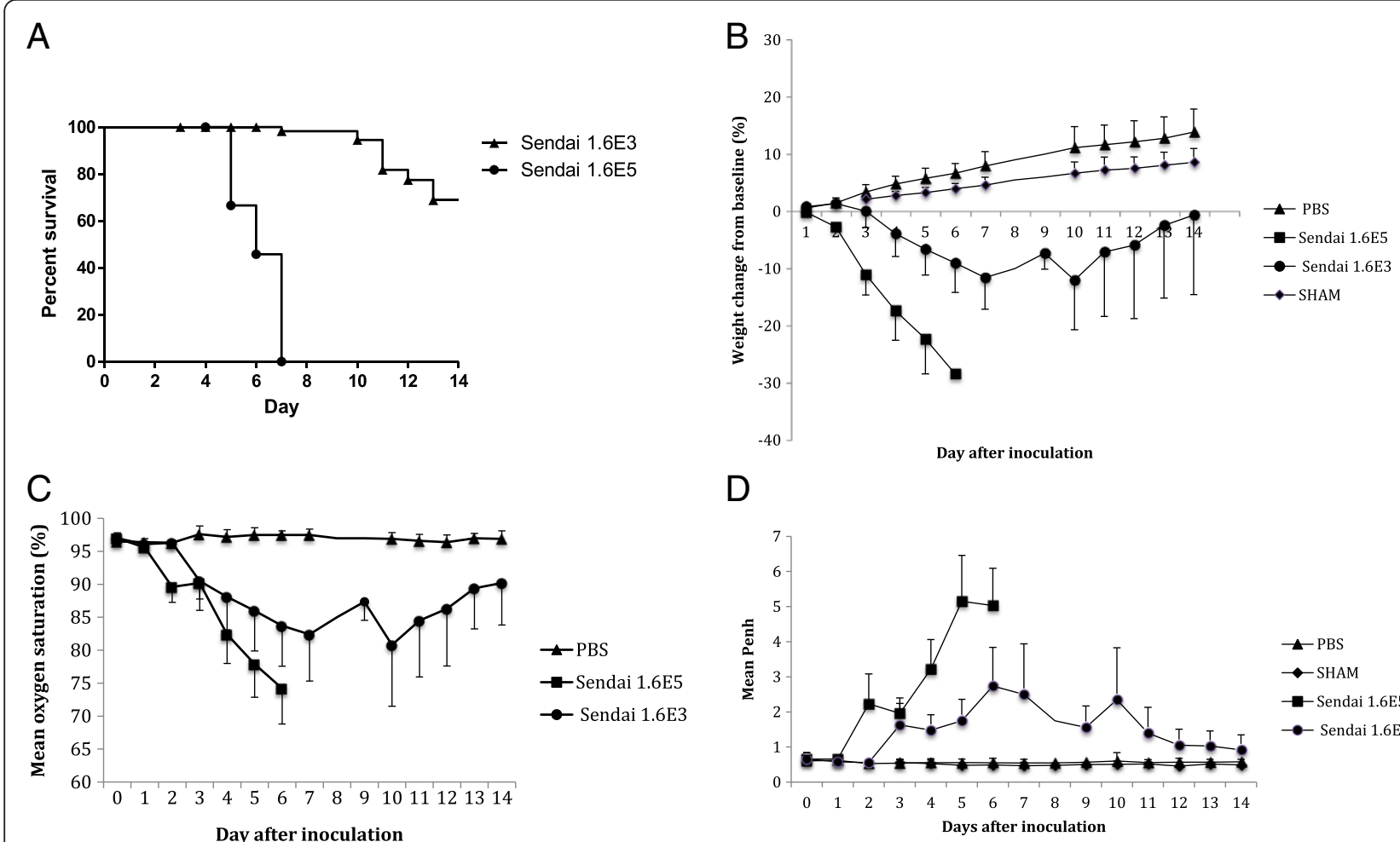

D

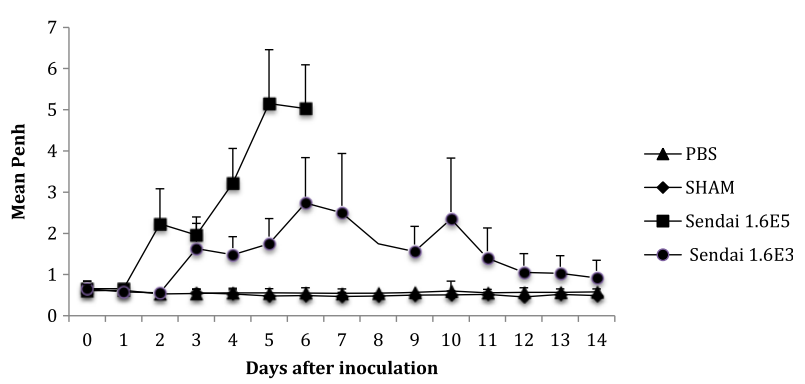

Figure 1 Clinical parameters. (A) Survival curve, (B) Mean weight change from baseline (\%), (C) Mean oxygen saturation (\%), (D) Mean enhanced pause (Penh) as measured by whole body plethysmography. PBS: phosphate buffered saline (control). SHAM: sham stock, prepared from uninfected mouse lung homogenate. In (A), there is statistical difference between the two survival curves $(p<0.05)$. In (B), (C), and (D), at all time points day 3 and later, clinical parameters of SeV-infected mice differed significantly from control mice inoculated with either PBS or sham stock ( $p<0.05$ via ANOVA analysis). There is no data for the mice inoculated with $1.6 \times 10^{5} \mathrm{IU}$ of SeV after day 5 due to death of the mice. $1.6 \mathrm{E} 5$ and 1.6E3: $1.6 \times 10^{5}$ and $1.6 \times 10^{3} \mathrm{IU}$ of SeV inoculated in $50 \mu$, respectively. Error bars represent standard deviation. 
5, oxygen saturations were as low as $74 \%$ and Penh values were at 7.5 -fold over baseline, although these clinical parameters were not statistically different from the other infected cohort (Figure 1).

\section{Virus replication in the lungs of SeV-infected mice}

Viral kinetics from the lungs of DBA/2 mice inoculated with $1.6 \times 10^{3}$ and $1.6 \times 10^{5} \mathrm{IU}$ of $\mathrm{SeV}$ are shown in Figure 2 . Despite greater weight loss and higher mortality rate in the mice inoculated with $1.6 \times 10^{5} \mathrm{IU}$ of $\mathrm{SeV}$, there was no difference in virus recovery between the two groups.

\section{Cellularity of bronchoalveolar lavage fluid from \\ SeV-infected mice}

Pulmonary cellularity of bronchoalveolar lavage fluid from $\mathrm{SeV}$-infected mice is shown in Figure 3. Increased pulmonary cellularity in Sendai infected mice, at both inoculations, is observed on days 3 and 5 followed by a reduction in cellular infiltrate at later time points. This increase in cellularity correlates with both clinical symptoms, such as weight loss and lung function, and production of pro-inflammatory mediators.

\section{Detection of pro-inflammatory mediators from lungs of SeV-infected mice}

Levels of CCL5, CCL11 (eotaxin), interferon- $\gamma$, CXCL10 (interferon gamma-induced protein 10 (IP-10)), and CCL3 $(\mathrm{MIP}-1 \alpha)$ detected in lung homogenates in response to $\mathrm{SeV}$-infection were significantly higher in the mice inoculated with $1.6 \times 10^{5} \mathrm{IU}$ when compared to those inoculated with $1.6 \times 10^{3}$ IU (Figure 4; $<<0.05$ ).
In lethal SeV infection, CCL3, CCL11, and interferon- $\Upsilon$ each strongly correlated with severity of clinical symptoms, including weight loss, diminished oxygen saturation, and Penh (Figures 5, 6 and 7). Interestingly, CCL5 correlated with weight loss $\left(R^{2}=0.86\right)$ and less so with diminished oxygen saturation $\left(R^{2}=0.54\right)$.

On the other hand, in mice inoculated with $1.6 \times 10^{3} \mathrm{IU}$ of $\mathrm{SeV}$, there was no correlation between proinflammatory mediators and clinical parameters. Correlation coefficient $\left(\mathrm{R}^{2}\right)$ for CCL11 and Penh, oxygen saturations, and weight loss were $0.02,0.006$, and 0.09 , respectively. $R^{2}$ for IFN- $\Upsilon$ and Penh, oxygen saturations, and weight loss were 0.19 , 0.26 , and 0.30 , respectively. $\mathrm{R}^{2}$ for CXCL10 and Penh, oxygen saturations, and weight loss were $0.27,0.41$, and 0.21 , respectively. $\mathrm{R}^{2}$ for CCL3 and Penh, oxygen saturations, and weight loss were $0.33,0.44$, and 0.59 , respectively. $R^{2}$ for CCL5 and Penh, oxygen saturations, and weight loss were $0.13,0.24$, and 0.10 , respectively.

Similarly, virus titers did not correlate with clinical parameters at either dose inoculum, with $\mathrm{R}^{2}$ of $0.57,0.58$, and 0.25 for Penh, oxygen saturation, and weight loss and inoculum of $1.6 \times 10^{5} \mathrm{IU}$ of $\mathrm{SeV}$, respectively, and $\mathrm{R}^{2}$ of $0.12,0.19$, and 0.44 for Penh, oxygen saturation, and weight loss and inoculum of $1.6 \times 10^{3} \mathrm{IU}$ of $\mathrm{SeV}$, respectively (data not in figure).

\section{Discussion}

In this study, we evaluated the clinical impact, virus recovery, and inflammatory responses to both lethal and sublethal $\mathrm{SeV}$ infections in inbred DBA/2 mice. As has been previously described, DBA/2 mice are highly susceptible to lethal infection with $\mathrm{SeV}$ [11,13-15]. Specifically, we

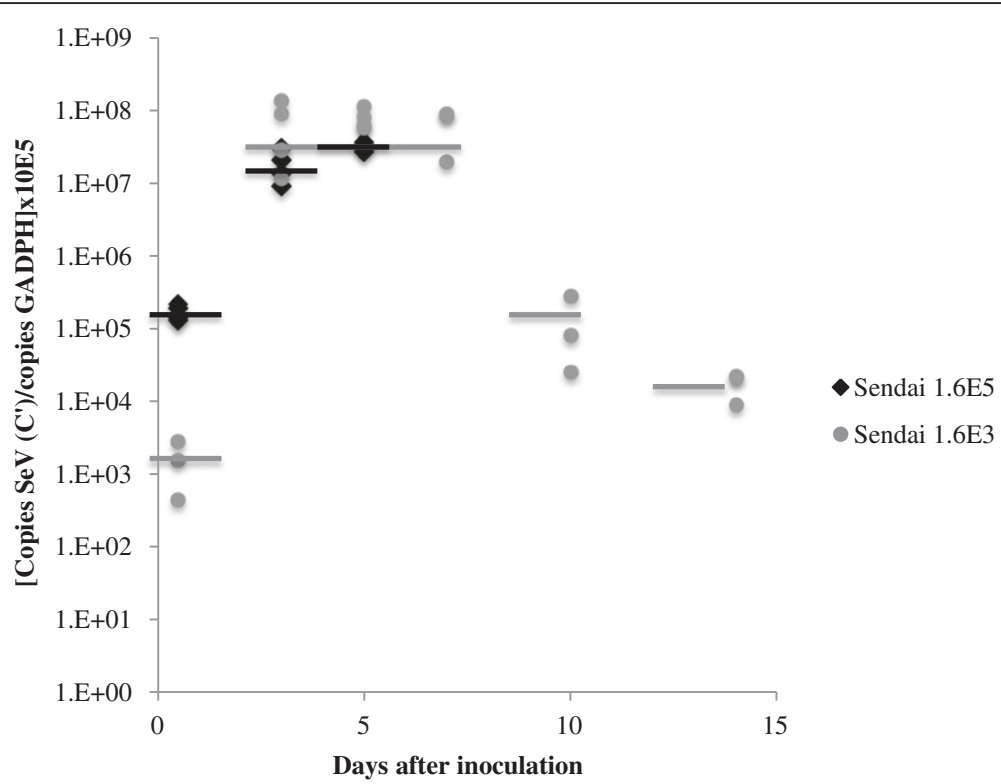

Figure 2 Virus recovery from mice inoculated with $1.6 \times 10^{3}$ or $1.6 \times 10^{5} \mathrm{IU}$ of Sendai virus. The day 0 lung virus titers were obtained immediately after inoculation. 1.6E5 and 1.6E3: $1.6 \times 10^{5} 1.6 \times 10^{3} \mathrm{IU}$ of SeV inoculated in $50 \mu \mathrm{l}$, respectively. 


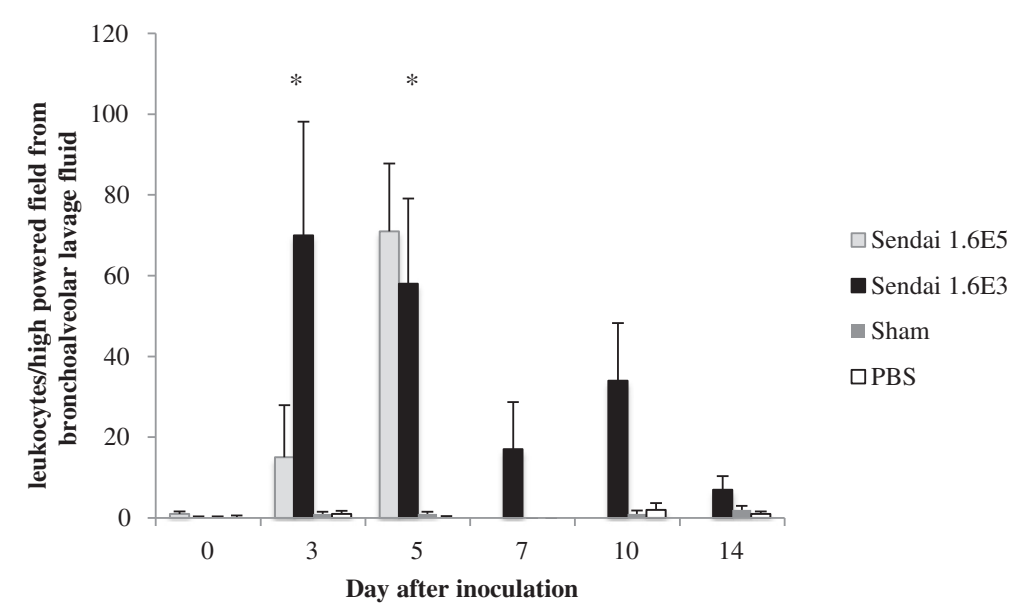

Figure 3 Cellularity of bronchoalveolar lavage fluid from mice inoculated with PBS, sham stock, $1.6 \times 10^{3}$ or $1.6 \times 10^{5} \mathrm{IU}$ of SeV. There is statistical difference between the cellularity of bronchoalveolar lavage fluid in SeV-infected mice at either inoculum and the control mice inoculated with either PBS or sham stock at all time points day 3 and later $(p<0.05)$. Data represent the mean leukocyte number counted from 40 high power fields of cytospin prepared bronchoalveolar fluids from 4 mice per group. ${ }^{*}$ represents statistical difference between cellularity of bronchoalveolar lavage fluid in SeV-infected mice inoculated with $1.6 \times 10^{3}$ and those inoculated with $1.6 \times 10^{5} \mathrm{IU}$ of SeV.

found that DBA/2 mice which received a higher titer virus inoculum $\left(1.6 \times 10^{5} \mathrm{IU}\right.$ of $\left.\mathrm{SeV}\right)$ sustained greater weight loss and mortality than the mice that received the lower inoculum $\left(1.6 \times 10^{3} \mathrm{IU}\right.$ of $\left.\mathrm{SeV}\right)$. Despite the increased severity of disease, virus recovery from mice receiving a lethal dose was not substantially different from that determined for mice receiving the lower virus inoculum. Interestingly, on day 3 post-inoculation, the mice receiving the lower inoculum had statistically higher BAL fluid cellularity when compared to the mice receiving the higher inoculum. The combination of these findings support the observation that severity of illness is not determined by virus recovery alone, and likely results from the combination of direct virus cytotoxicity and the subsequent, host inflammatory response [11,13-15].

The inflammatory response to $\mathrm{SeV}$ in the mice differed based on the inoculum. The DBA/2 mice inoculated with $1.6 \times 10^{5} \mathrm{IU}$ of $\mathrm{SeV}$ developed a more robust inflammatory response, eliciting higher local levels of CCL11, interferon- $\gamma$, CCL3, CCL5, and CXCL10 when compared to mice inoculated with $1.6 \times 10^{3} \mathrm{IU}$ of $\mathrm{SeV}$, despite similar peak virus titers. It is possible that significant differences in early virus kinetics led to the differences in the chemokine response. While this observation is unusual, it is not unique to this study. There are several well-documented parallels demonstrating that there are host- and virus-specific contributions to virus kinetics and resulting chemokine response. Neonatal and adult mice inoculated with the same dose of pneumovirus of mice (PVM), similar to mice of the same strain and age inoculated with either PVM strain 15 or PVM strain J3666, develop differing chemokine responses despite similar virus replication $[16,17]$.

In the lethal infection, CCL11, interferon- $\gamma$, and CCL3 each strongly correlated with worsening clinical symptoms, including weight loss, diminished oxygen saturation, and increasing Penh. While interferon- $\gamma$ and CCL3 are among the mediators identified previously in response to $\mathrm{SeV}$ infection $[11,12,18]$, here we correlate production with specific clinical parameters.

CCL11, CCL3, and interferon- $\gamma$, are also produced in response to other paramyxovirus infections, including PVM and human RSV infections [19-26]. Furthermore, Jaffri showed that these three pro-inflammatory mediators correlated with worsening histopathologic score and higher Penh values in RSV-challenged mice [25].

Identifying mediators which correlate with disease severity provide targets for therapeutic interventions. In RSV-challenged mice, for example, the use of blocking antibody to CCL11, an eosinophil chemoattractant, resulted in reduced pulmonary eosinophilia and disease severity [23]. Similarly, PVM-infected mice genetically deficient in CCL3 have reduced lung inflammation, although higher lung virus titers, when compared to wild-type mice, suggesting that the inflammatory response induced by CCL3, while potentially harmful to the host, is needed to attenuate virus replication [26]. Treatment of PVM-infected mice with a chemokine receptor antagonist that blocks interaction between CCL3/MIP-1 $\alpha$ and its receptor CCR1, in combination with antiviral therapy, results in significant reductions in morbidity and mortality when compared to untreated PVM-infected mice [27]. 

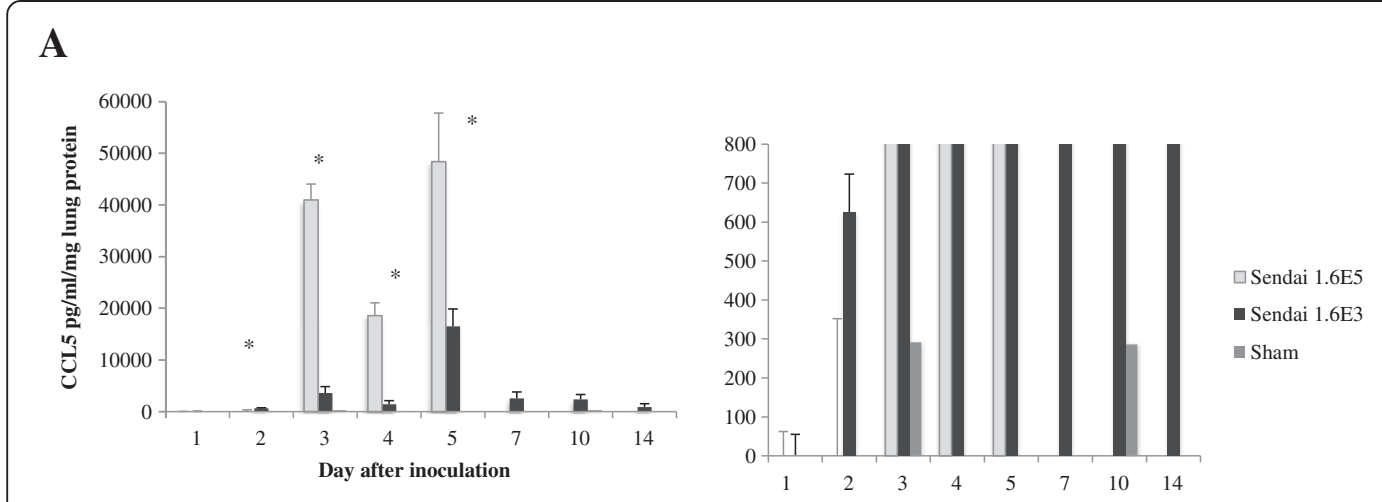

B

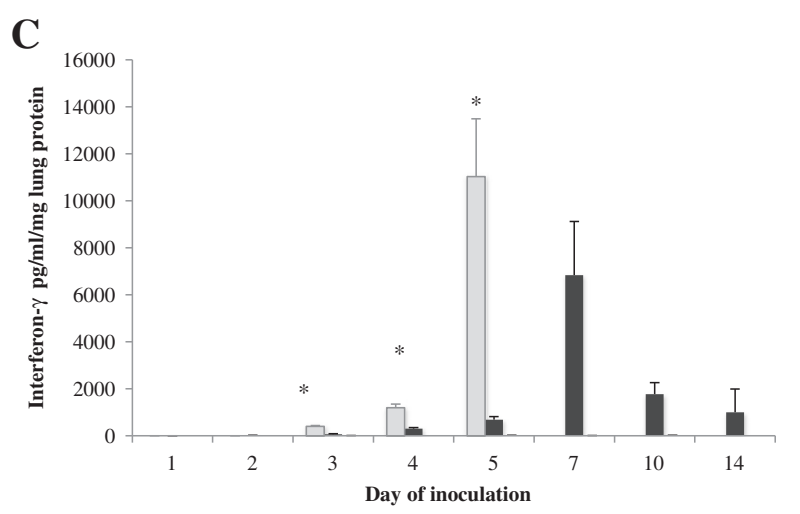

D

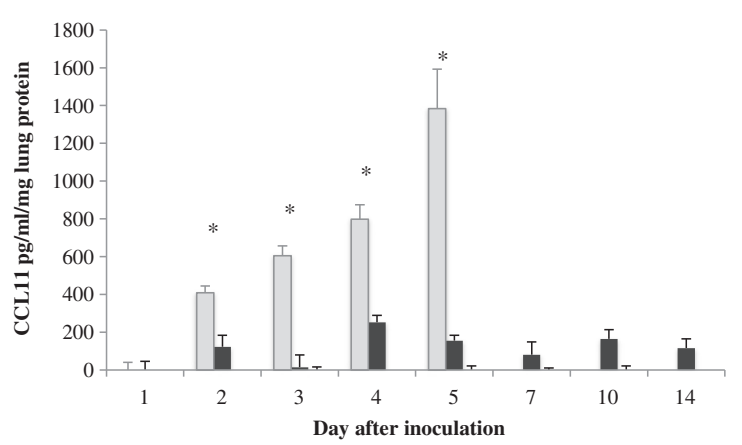

$\mathbf{E}$
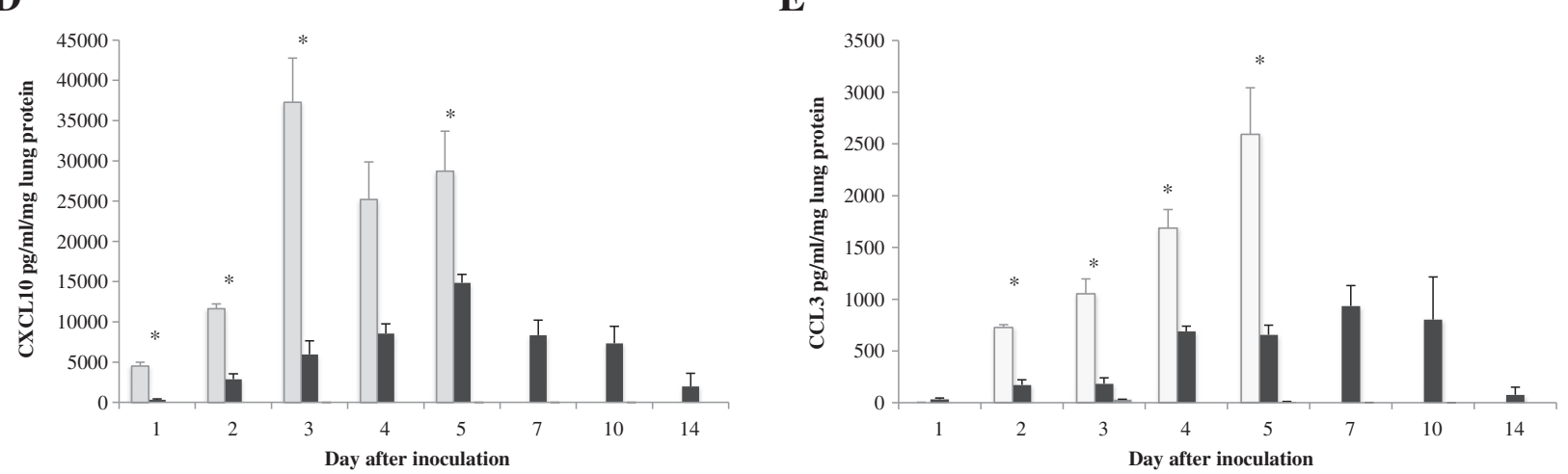

Figure 4 Detection of pro-inflammatory mediators in lungs of mice inoculated with $1.6 \times 103$ or $1.6 \times 105 \mathrm{IU}$ of SeV or sham stock. There is no data for the mice inoculated with $1.6 \times 105 \mathrm{IU}$ of SeV after day 5 due to death of the mice. (A) CCL5. The graph on the left represents the complete data set for CCL5 production in all three groups. The graph on the right is an expanded view of the same data set to easily visualize the difference in CCL5 production between the mice inoculated with $1.6 \times 10 \wedge 3$ and $1.6 \times 10 \wedge 5 \mathrm{IU}$ of SeV at day 2. (B) CCL11 (C) Interferon- $\gamma$ (D) CXCL10, (E) CCL3 ${ }^{*} p<0.05$ when comparing mice inoculated with $1.6 \times 103$ and $1.6 \times 105 \mathrm{IU}$ of SeV. At all time points with each inflammatory mediator measured, there is statistical difference between the SeV infected mice and the mice inoculated with sham stock ( $p<0.05)$. 1.6E5 and 1.6E3: 1.6×105 1.6x103 IU of SeV inoculated in $50 \mu$ l, respectively.

\section{Conclusions}

We have described here the inflammatory responses to lethal and sublethal inocula in DBA/2 mice and have shown that CCL11, CCL3, and interferon- $\gamma$ each correlate with disease severity. Further understanding of these responses in the murine model of severe PIV lower respiratory tract infection will aid in the development of therapeutic agents for human disease.

\section{Methods}

Viral stocks

Six to eight week old DBA/2 mice (Charles River, Wilmington, MA) were intra-nasally inoculated with $\mathrm{SeV}$ strain 52, obtained from American Type Culture Collection (ATCC, Manassas, VA). Infected mouse lungs were harvested 5 days post-inoculation, homogenized, pooled, clarified via centrifugation, aliquoted, and stored 
A.

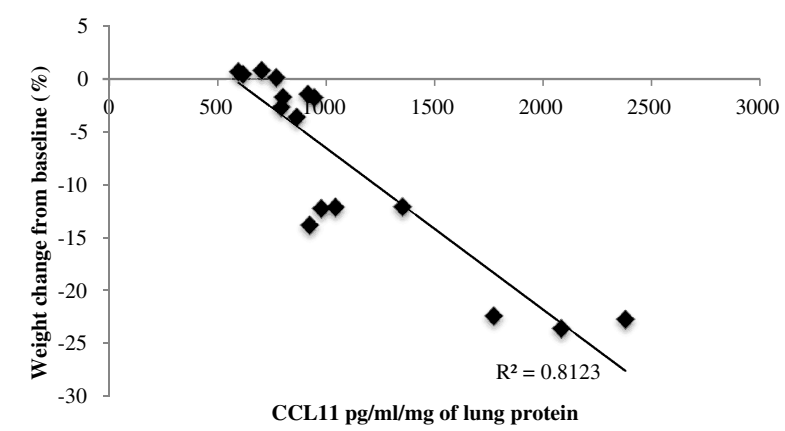

C.

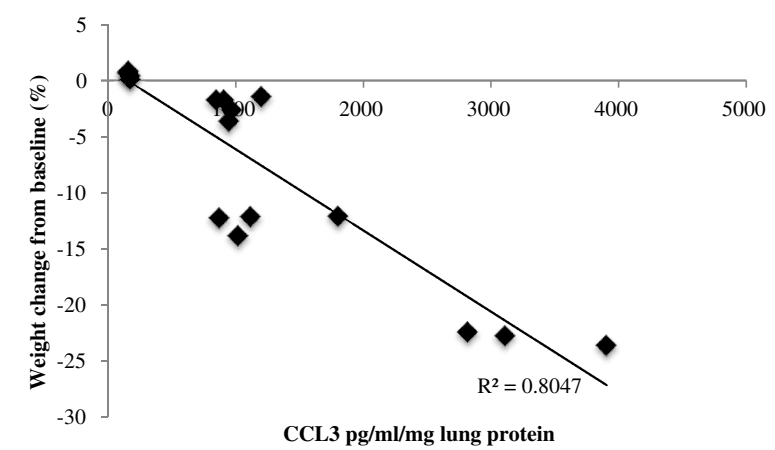

E.

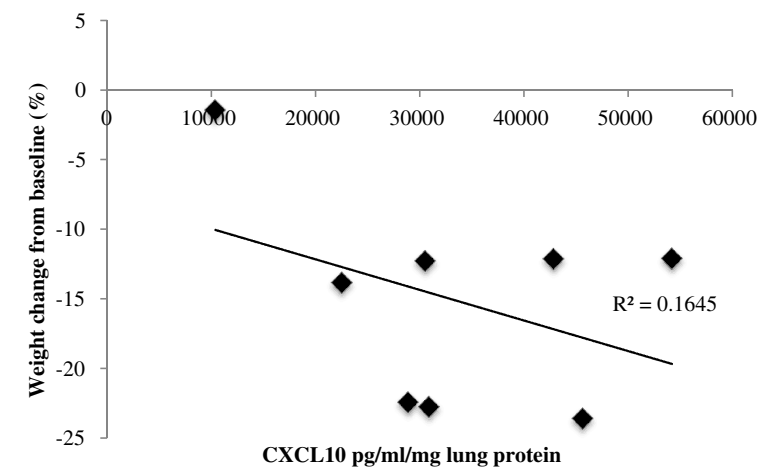

B.

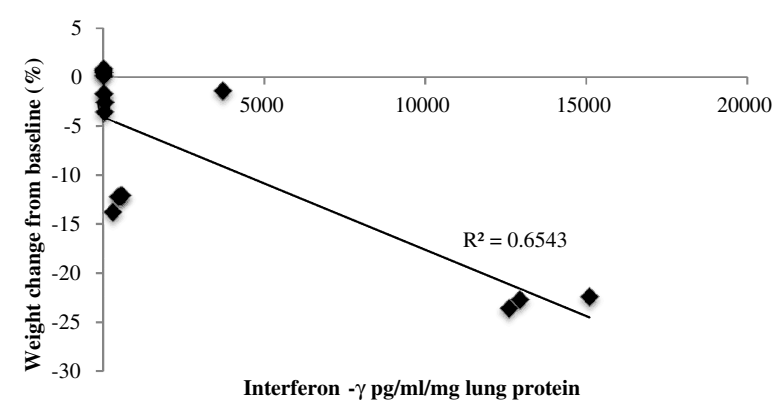

D.

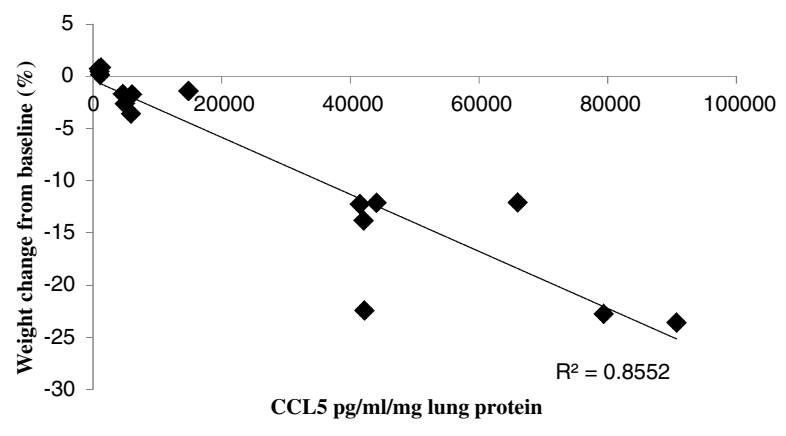

Figure 5 Scatter plots of concentrations of (A) CCL11, (B) interferon- $Y$, (C) CCL3, (D) CCL5, and (E) CXCL10 against weight loss in mice inoculated with $1.6 \times 105 \mathrm{IU}$ of Sendai virus. Data was collected over 14 days. R2 is the correlation coefficient.

in liquid nitrogen. All procedures were reviewed an approved by the institution's Committee for the Humane Use of Animals (CHUA 191). In total, $128 \mathrm{DBA} / 2$ mice were inoculated with $1.6 \times 10^{3} \mathrm{IU}$ of $\mathrm{SeV}$ over 7 experiments and $52 \mathrm{DBA} / 2$ mice were inoculated with $1.6 \times 10^{5} \mathrm{IU}$ of $\mathrm{SeV}$ over 3 experiments to collect the following data.

\section{Sham stocks}

Lungs from uninfected 6-8 week old DBA/2 mice purchased from Charles River (Wilmington, MA) were harvested 5 days post-inoculation, homogenized, pooled, clarified via centrifugation, aliquoted, and stored in liquid nitrogen and used as sham stock control.

\section{Establishing infection in mice}

Specific pathogen-free, 5-8 week old DBA/2 mice were purchased from Charles River (Wilmington, MA). Virus stocks of mouse passaged $\mathrm{SeV}$ stored in liquid nitrogen were diluted in phosphate buffered saline (PBS) to final concentrations of $1.6 \times 10^{3}$ and $1.6 \times 10^{5}$ infectious units (IU)/50 $\mu$ l. Under light isofluorane anesthesia, the DBA/2 mice were intranasally inoculated with either $1.6 \times 10^{3}$ or $1.6 \times 10^{5} \mathrm{IU}$ in $50 \mu \mathrm{l}$. Control mice received either an intranasal dose of PBS diluent or sham stock $(50 \mu \mathrm{l})$.

Clinical symptoms, as per scoring system previously described, together with body weights, and pulse oximetry were recorded daily [28]. Whole body plethysmography 


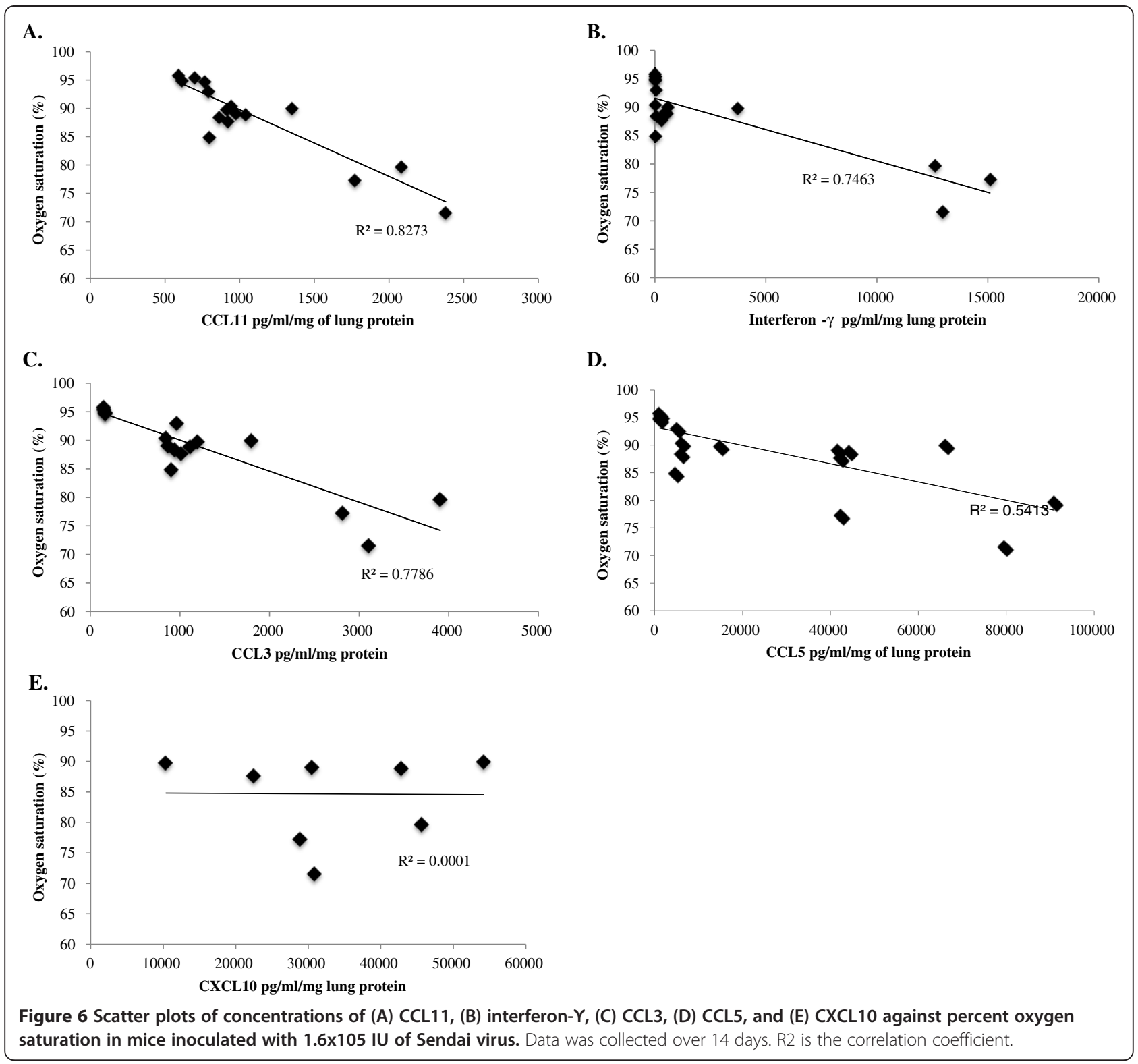

(WBP) was performed daily for a 5-minute period, as previously described, and measured enhanced pause (Penh) values were recorded [28,29]. Oxygen saturations were measured daily using a throat clip pulse oximeter (Starr Life Sciences Corp, Oakmont, PA). One day prior to inoculation, hair at the site of the oximeter sensor was removed using a depilatory cream. At the time of daily oximetry measurements, the appropriate-sized throat clip was applied to the unanesthetized mouse. Pulse oximetry, heart rates, and respiratory rates were recorded.

\section{Determination of virus titers in SeV-infected mouse lung} tissue

Virus titers were determined on days $0,3,5,7,10$, and 14 after intranasal inoculation with $\mathrm{SeV}$ by a quantitative reverse transcriptase PCR assay that targets the $\mathrm{SeV} \mathrm{C}^{\prime}$ gene. Lung tissue was excised from $\mathrm{SeV}$-infected mice, homogenized in RNazol B and RNA prepared per manufacturer's instructions. Integrity of the RNA was evaluated on formaldehyde agarose gels and quantified spectrophotometrically $\left(\mathrm{A}_{260} / \mathrm{A}_{280}\right)$. cDNA was prepared from $2 \mu \mathrm{g}$ DNase I-treated RNA from each lung sample and subjected to quantitative RT-PCR using primers and probe targeting the virus C' gene: probe: 5 '-56FAM-ACTTCTC CTTCGCCCTCACTT 36TAMSp-3', primer 1: 5' -AACA CCAATCAACACTCCCC-3', primer 2: 5' -CCTGATCG ATTATCTTGGGTC-3', with reference to a standard curve generated using serial ten-fold dilutions of the C' gene as target. The cDNAs were then subjected to a second set of quantitative PCR assays, with the commercial 


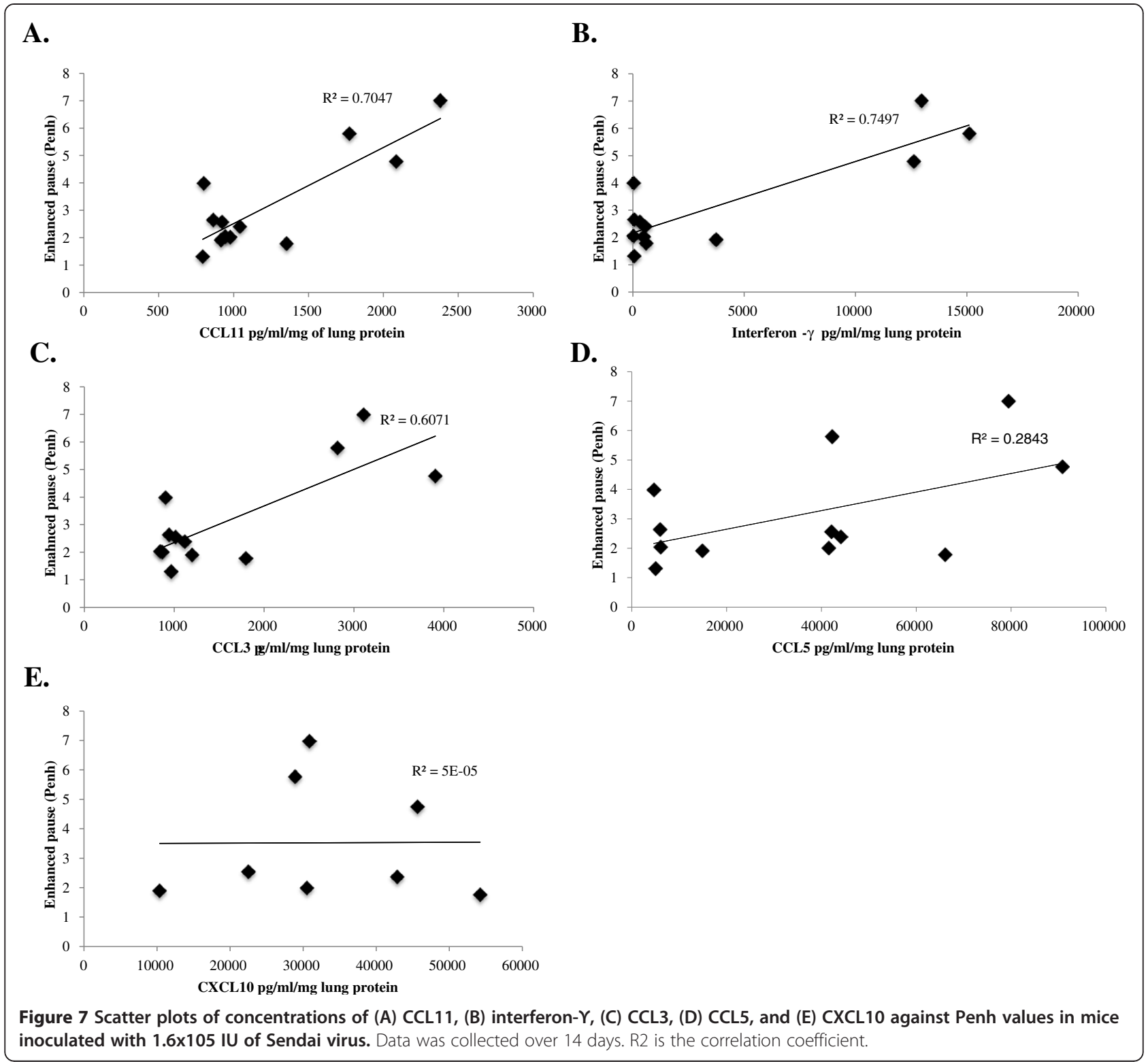

rodent GAPDH primers and probe (Applied Biosciences, Foster City, CA) and serial ten-fold dilutions of the $905 \mathrm{bp}$ rodent GAPDH fragment (Applied Biosciences, Foster City, CA) to generate a standard curve. Controls include reactions with no reverse transcriptase and no template. Reactions were performed in an ABI 7500 Sequence detector, with cycling parameters including: $50^{\circ} \mathrm{C}$ for $2 \mathrm{~min}$, $95^{\circ} \mathrm{C}$ for $10 \mathrm{~min}$, followed by 40 cycles of $95^{\circ} \mathrm{C}$ for $15 \mathrm{~s}$ and $65^{\circ} \mathrm{C}$ for $1 \mathrm{~min}$. Data are expressed as copies of $\mathrm{C}^{\prime}$ per $10^{5}$ copies GAPDH.

\section{Bronchoalveolar lavage fluid and cell counts}

At given time points, mice were euthanized (four mice per condition per time point), and bronchoalveolar lavage (BAL) fluid was harvested by transtracheal instillation of pre-chilled PBS with 2\% EDTA, with recovery of approximately $700 \mu \mathrm{l}$ of BAL fluid. Leukocyte counts were obtained by visual inspection and quantitative analysis cytospin preparations that were stained following Fisher Scientific Hema 3 protocol.

\section{Determination of concentrations of proinflammatory} mediators and growth factors from SeV-infected mouse lungs

Concentrations of proinflammatory mediators, including CCL5, CCL11, interferon- $\gamma$, CXCL10, and CCL3 were determined on days $0,1,2,3,4,5,7,10$, and 14 on total lung homogenates from $\mathrm{SeV}$-, sham stock-, and diluent control-inoculated mice (four mice each per time point) 
using commercially-available ELISA kits (R\&D Systems, Minneapolis, MN).

\section{Statistical analysis}

Data were analyzed using ANOVA or Student t-test's as appropriate.

\section{Competing interests}

The authors have no competing interests to declare.

\section{Authors' contributions}

MS participated in the design of the study, performing experiments, data analysis and interpretation, and drafted the manuscript. CB participated in the design of the study and performing experiments. HR participated in the design of the study, interpretation of the data, and critical review of the manuscript. JD participated in the design of the study, data analysis and interpretation, and critical review of the manuscript. All authors have read and approved the final manuscript.

\section{Author details}

'Department of Pediatrics, SUNY Upstate Medical University, 750 East Adams Street, Syracuse, NY 13210, USA. ${ }^{2}$ Laboratory of Allergic Diseases, National Institute of Allergy and Infectious Diseases, National Institutes of Health Bethesda, Maryland 20892, USA.

Received: 25 June 2013 Accepted: 10 December 2013

Published: 21 December 2013

\section{References}

1. Welliver RC: Bronchiolitis and Infectious Asthma. In Textbook of Pediatric Infectious Diseases. 6th edition. Edited by Feigin RD, Cherry JD, DemmlerHarrison GJ, Kaplan SL. Philadelphia: Saunders Elsevier; 2009:277-288.

2. Hall CB: Respiratory syncytial virus and parainfluenza virus. N Engl J Med 2001, 344:1917-1928.

3. Iwane MK, Edwards KM, Szilagyi PG, Walker FJ, Griffin MR, Weinberg GA, Coulen C, Poehling KA, Shone LP, Balter S, Hall CB, Erdman DD, Wooten K, Schwartz B, New Vaccine Surveillance Network: Population-based surveillance for hospitalizations associated with respiratory syncytial virus, influenza virus, and parainfluenza viruses among young children. Pediatrics 2004, 113:1758-1764.

4. Weinberg GA, Hall CB, Iwane MK, Poehling KA, Edwards KM, Griffin MR, Staat MA, Curns AT, Erdman DD, Szilagyi PG, New Vaccine Surveillance Network: Parainfluenza virus infection of young children: estimates of the population-based burden of hospitalization. J Pediatr 2009, 154:694-699.

5. Sparrow A, Geelhoed G: Prednisolone versus dexamethasone in croup: a randomised equivalence trial. Arch Dis Child 2006, 91:580-583.

6. Geelhoed GC, Turner J, Macdonald WB: Efficacy of a small single dose of oral dexamethasone for outpatient croup: a double blind placebo controlled clinical trial. BMJ 1996, 313:140-142.

7. Russell KF, Liang Y, O'Gorman K, Johnson DW, Klassen TP: Glucocorticoids for croup. Cochrane Database Syst Rev 2011, 19, CD001955.

8. Schomacker H, Schaap-Nutt A, Collins PL, Schmidt AC: Pathogenesis of acute respiratory illness caused by human parainfluenza viruses. Curr Opin Virol 2012, 2:294-299.

9. El Feghaly RE, McGann L, Bonville CA, Branigan PJ, Suryadevara M, Rosenberg HF, Domachowske JB: Local production of inflammatory mediators during childhood parainfluenza virus infection. Pediatr Infect Dis J 2010, 29:e26-e31.

10. Faisca P, Desmecht D: Sendai virus, the mouse parainfluenza type 1: A longstanding pathogen that remains up-to-date. Res Vet Sci 2007, 82:115-125.

11. Simon AY, Sasaki N, Ichii O, Kajino K, Kon Y, Agui T: Distinctive and critical roles for cellular immunity and immune-inflammatory response in the immunopathology of Sendai virus infection in mice. Microbes Infect 2011 13:783-797.

12. Mo XY, Sarawar SR, Doherty PC: Induction of cytokines in mice with parainfluenza pneumonia. J Virol 1995, 69:1288-1291.

13. Simon AY, Moritoh K, Torigoe D, Asano A, Sasaki N, Agui T: Multigenic control of resistance to Sendai virus infection in mice. Infect Genet Evol 2009, 9:1253-1259.
14. Brownstein DG, Smith AL, Johnson EA: Sendai virus infection in genetically resistant and susceptible mice. Am J Pathol 1981, 105:156-163.

15. Itoh $\mathrm{T}$, Iwai $\mathrm{H}$, Ueda $\mathrm{K}$ : Comparative lung pathology of inbred strains of mice resistant and susceptible to Sendai virus infection. J Vet Med Sci 1991, 53:275-279.

16. Bonville CA, Ptaschinski C, Percopo CM, Rosenberg HF, Domachowske JB: Inflammatory responses to acute pneumovirus infection in neonatal mice. Virol J 2010, 15:320.

17. Domachowske JB, Bonville CA, Easton AJ, Rosenberg HF: Differential expression of proinflammatory cytokine genes in vivo in response to pathogenic and nonpathogenic pneumovirus infections. J Infect Dis 2002, 186:8-14.

18. Hua J, Mei-June L, Rashidbaigi A: Cytokines induced by Sendai virus in human peripheral blood leukocytes. J Leukoc Biol 1996, 60:125-128.

19. Amanatidou V, Zaravinos A, Apostolakis S, Spandidos DA: Chemokines in respiratory viral infections: focus on their diagnostic and therapeutic potential. Crit Rev Immunol 2011, 31:341-356.

20. Haeberle HA, Kuziel WA, Dieterich HJ, Casola A, Gatalica Z, Garofalo RP: Inducible expression of inflammatory chemokines in respiratory syncytial virus-infected mice: role of MIP-1alpha in lung pathology. J Virol 2001, 75:878-890

21. Harrison AM, Bonville CA, Rosenberg HF, Domachowske JB: Respiratory syncytial virus-induced chemokine expression in the lower airways: eosinophil recruitment and degranulation. Am J Respir Dis Crit Care Med 1999, 159:1918-1924.

22. Sheeran P, Jafri H, Carubelli C, Saavedra J, Johnson C, Krisher K, Sanchez PJ, Ramilo O: Elevated cytokine concentrations in the nasopharyngeal and tracheal secretions of children with respiratory syncytial virus disease. Pediatr Infect Dis J 1999, 18:115-122.

23. Matthews SP, Tregoning JS, Coyle AJ, Hussell T, Openshaw PJ: Role of CCL11 on eosinophilic lung disease during respiratory syncytial virus infection. J Virol 2005, 79:2050-2057.

24. Kim CK, Callaway Z, Koh YY, Kim SH, Fujisawa T: Airway IFN-Y production during RSV bronchiolitis is associated with eosinophilic inflammation. Lung 2012, 190:183-188.

25. Jaffri HS, Chavez-Bueno S, Mejias A, Gomez AM, Rios AM, Nassi SS, Yusuf M, Kapur P, Hardy RD, Hatfield J, Rogers BB, Krisher K, Ramilo O: Respiratory syncytial virus induces pneumonia, cytokine response, airway obstruction, and chronic inflammatory infiltrates associated with long-term airwayhyperresponsiveness in mice. J Infect Dis 2004, 189:1856-1865.

26. Domachowske JB, Bonville CA, Gao JL, Murphy PM, Easton AJ, Rosenberg HF: The chemokine macrophage-inflammatory protein-1 $a$ and its receptor CCR1 control pulmonary inflammation and antiviral host defense in paramyxovirus infection. J Immunol 2000, 165:2677-2682.

27. Bonville CA, Lau VK, DeLeon JM, Gao JL, Easton AJ, Rosenberg HF, Domachowske JB: Functional antagonism of chemokine receptor CCR1 reduces mortality in acute pneumovirus infection in vivo. J Virol 2004, 78:7984-7989.

28. Bonville CA, Bennett NJ, Koehnlein M, Haines DM, Ellis JA, DelVecchio AM, Rosenberg HF, Domachowske JB: Respiratory dysfunction and proinflammatory chemokines in the pneumonia virus of mice (PVM) model of viral bronchiolitis. Virology 2006, 349:87-95.

29. Bonville CA, Bennett NJ, Percopo CM, Branigan PJ, Del Vecchio AM, Rosenberg HF, Domachowske JB: Diminished inflammatory responses to natural pneumovirus infection among older mice. Virology 2007, 368:182-190.

\section{doi:10.1186/1743-422X-10-357}

Cite this article as: Suryadevara et al: Local production of CCL3, CCL11, and IFN- $\gamma$ correlates with disease severity in murine parainfluenza virus infection. Virology Journal 2013 10:357. 